\title{
GAMBARAN KELELAHAN DAN KELUHAN MUSKULOSKELETAL PADA PENGEMUDI BUS MALAM JARAK JAUH PO. RESTU MULYA
}

\author{
Rahmadi Fahmi \\ Ikatan Alumni Kesehatan Masyarakat Indonesia (IAKMI) Provinsi Jawa Timur \\ E-mail: rahmadifahmi@gmail.com
}

\begin{abstract}
Long trip night bus drivers is a very highly risk of fatigue and musculoskeletal disorder. The aim of this research was to learn and acknowledging the level of fatigue and musculoskeletal disorder in PO. (Perusahaan Otobus) Restu Mulya long trip night bus drivers. This is an observational descriptive research with cross sectional study design. The research's variable is the level of fatigue and musculoskeletal disorder that obtained from primary data using SSRT (Subjective Self Rating Test) questionnaire and NBM (Nordic Body Map) questionnaire. The result shows that 58.33\% long trip night bus drivers was felt a moderate level of fatigue and $41.67 \%$ long trip night bus drivers felt a severe level of fatigue. Most of long trip night bus drivers which number 75\% drivers felt almost-sick of musculoskeletal disorder with the buttock, back, neck, and leg symptom point. The fatigue in PO. Restu Mulya long trip night bus drivers was a moderate and severe level with a lower activity and physicly fatigue symptom. The fatigue can be possibly caused by high physical work burden and psycologycal work burden which is a big responsibilities for the passengers safety. Then a low level of musculoskeletal disorders with the buttock, back, neck, and leg symptom point that possibly caused by monotony sit work posture on a very long time.
\end{abstract}

Keywords: long trip night bus drivers, fatigue, musculoskeletal disorder

\begin{abstract}
ABSTRAK
Pengemudi bus malam jarak jauh merupakan pekerjaan yang memiliki risiko yang sangat tinggi terhadap timbulnya kelelahan dan keluhan muskuloskeletal. Tujuan dari penelitian ini adalah untuk mengetahui serta mempelajari tingkat kelelahan dan keluhan muskuloskeletal yang dirasakan oleh para pengemudi bus malam jarak jauh PO. (Perusahaan Otobus) Restu Mulya. Penelitian ini merupakan penelitian observasional deskriptif dengan desain studi cross sectional. Varibel dalam penelitian ini adalah tingkat kelelahan dan keluhan muskuloskeletal yang didapatkan dari data primer melalui kuesioner SSRT (Subjective Self Rating Test) dan kuesioner NBM (Nordic Body Map). Hasil penelitian menunjukkan $58,33 \%$ pengemudi bus malam jarak jauh mengalami kelelahan sedang dan $41,67 \%$ pengemudi bus malam jarak jauh mengalami kelelahan berat. Sebagian besar pengemudi bus malam jarak jauh yaitu sebanyak $75 \%$ mengalami keluhan muskuloskeletal agak sakit dengan titik keluhan yaitu pantat, punggung, leher dan betis kaki. Kelelahan yang dialami oleh pengemudi bus malam jarak jauh PO. Restu Mulya merupakan kelelahan dengan tingkat sedang dan berat, dengan gejala pelemahan kegiatan dan kelelahan fisik. Penyebab kelelahan yang sangat memungkinkan adalah beban kerja fisik yang sangat tinggi dan beban kerja mental yang besar terhadap keselamatan penumpangnya. Sedangkan keluhan muskuloskeletal yang dirasakan oleh pengemudi bus malam jarak jauh PO. Restu Mulya adalah keluhan tingkat ringan dengan titik keluhan yaitu pantat, punggung, leher dan betis kaki. Penyebab keluhan muskuloskeletal yang sangat memungkinkan adalah sikap kerja duduk dan monoton dalam waktu yang sangat lama.
\end{abstract}

Kata Kunci: pengemudi bus malam jarak jauh, kelelahan, keluhan muskuloskeletal

\section{PENDAHULUAN}

Pekerjaan mengemudi merupakan suatu pekerjaan yang membutuhkan tingkat konsentrasi tinggi karena memerlukan koordinasi yang cepat dan tepat antara mata, tangan, kaki, dan otak, sehingga mengemudi merupakan suatu pekerjaan yang sangat berisiko tinggi mengalami kelelahan dan berbagai gangguan kesehatan lainnya (Yogisutanti dkk, 2013).

Salah satu kelompok masyarakat pekerja yang memiliki risiko tinggi terhadap terjadinya kelelahan dan gangguan kesehatan adalah para pengemudi bus malam jarak jauh. Waktu tempuh yang sangat lama untuk perjalanan jarak jauh pada malam hari, dengan sedikitnya waktu istirahat di saat kerja, disertai dengan tanggung jawab yang sangat besar terhadap keselamatan penumpang merupakan beban kerja fisik dan psikologis yang dapat menyebabkan monotoni dan kebosanan serta berpengaruh terhadap kelelahan. Posisi duduk dalam waktu yang sangat lama saat mengemudi juga dapat menimbulkan 
beberapa gangguan kesehatan terutama keluhan muskuloskeletal (Tarwaka dkk, 2004).

Kondisi ini diperparah dengan gaya hidup kurang sehat pada pengemudi bus malam seperti pola makan dan istirahat yang tidak teratur, rendahnya kebiasaan olahraga, tingginya kebiasaan merokok dan mengonsumsi minuman beralkohol, serta karakteristik individu yang berbeda-beda dari setiap pengemudi sehingga sangat memungkinkan terjadinya kelelahan dengan tingkat berat dan gangguan kesehatan seperti keluhan muskuloskeletal (Namira dan Nurhayati, 2014).

Kelelahan merupakan suatu mekanisme alamiah tubuh yang menunjukkan bahwa tubuh membutuhkan waktu istirahat untuk pemulihan kembali stamina dan tenaga yang telah terpakai selama bekerja (Tarwaka, 2010). Kelelahan yang timbul pada pekerja dapat menyebabkan menurunnya efisiensi dan performa kerja, serta pelemahan kekuatan dan ketahanan fisik sehingga tubuh tidak sanggup untuk melanjutkan pekerjaannya (Setyawati, 2010).

Kondisi kelelahan pada pengemudi bus malam jarak jauh akan mengganggu aktivitas kerja mengemudi yang dilakukan oleh pengemudi bus malam jarak jauh dan dapat sangat berbahaya yaitu akan berakibat fatal berupa kecelakaan serta menimbulkan berbagai kerugian baik kerugian material maupun kerugian non material akibat kecelakaan (Suma'mur, 2009).

Keluhan muskuloskeletal merupakan suatu gangguan yaitu berupa rasa nyeri pada otot skeletal (otot rangka) yang dapat diakibatkan karena pembebanan otot statis yang berat dan berulang serta dalam waktu yang cukup lama. Keluhan muskuloskeletal yang timbul dan dirasakan oleh pekerja memiliki tingkatan dari ringan hingga sangat sakit (Tarwaka dkk, 2004).

Perjalanan jauh yang ditempuh dengan waktu yang sangat lama oleh setiap pengemudi bus malam jarak jauh akan menimbulkan pembebanan otot statis pada beberapa titik otot sehingga meningkatkan risiko timbulnya keluhan muskuloskeletal pada pengemudi bus malam jarak jauh.

Hal inilah yang mendorong minat peneliti untuk melakukan sebuah studi terhadap tingkat kelelahan dan keluhan muskuloskeletal pada pengemudi bus malam jarak jauh PO. Restu Mulya. Tujuan dari penelitian ini adalah untuk mengetahui serta mempelajari tingkat kelelahan dan tingkat keluhan muskuloskeletal pada pengemudi bus malam jarak jauh PO. Restu Mulya.

\section{METODE}

Penelitian ini adalah sebuah penelitian observasional deskriptif dengan desain studi cross sectional. Teknik pengambilan sampel yang digunakan adalah total populasi yaitu sebanyak 12 orang dari populasi penelitian yaitu seluruh pengemudi bus malam jarak jauh PO. Restu Mulya jurusan Surabaya-Denpasar yang berjumlah 17 orang pengemudi. Sebanyak 5 orang pengemudi bus malam jarak jauh PO. Restu Mulya dieksklusi karena 3 orang diantaranya merupakan pengemudi bus cadangan dan tidak hanya melayani satu rute trayek jurusan Surabaya-Denpasar sehingga tidak termasuk dalam kriteria responden penelitian, serta 2 orang pengemudi lainnya tidak bersedia untuk dijadikan responden penelitian.

Variabel dalam penelitian ini adalah tingkat kelelahan dan keluhan muskuloskeletal yang didapatkan dari data primer. Pengumpulan data primer dilakukan pada bulan April-Mei tahun 2015 di lokasi penelitian yaitu Kantor Perwakilan PO. Restu Mulya cabang Surabaya yang terletak di Jalan Makam Peneleh nomor 45 Surabaya, dengan menggunakan kuesioner kelelahan SSRT (Subjective Self Rating Test) untuk data tingkat kelelahan dan kuesioner keluhan muskuloskeletal NBM (Nordic Body Map) untuk data keluhan muskuloskeletal pada pengemudi bus malam jarak jauh PO. Restu Mulya. Kriteria penilaian untuk kelelahan dapat dilihat pada Tabel 1.

Tabel 1. Kriteria Nilai Tingkat Kelelahan pada Kuesioner SSRT

\begin{tabular}{cc}
\hline Nilai Kelelahan & Tingkat Kelelahan \\
\hline $30-52$ & Ringan \\
$53-75$ & Sedang \\
$76-98$ & Berat \\
$91-120$ & Sangat berat \\
\hline
\end{tabular}

Kriteria penilaian keluhan muskuloskeletal dapat dilihat pada Tabel 2.

Tabel 2. Kriteria Nilai Tingkat Keluhan Muskuloskeletal pada Kuesioner NBM

\begin{tabular}{cc}
\hline Nilai Keluhan & Tingkat Kelelahan \\
\hline $28-49$ & Tidak sakit \\
$50-70$ & Agak sakit \\
$71-92$ & Sakit \\
$93-112$ & Sangat sakit \\
\hline
\end{tabular}


Hasil penelitian akan disajikan didalam tabel dan dideskripsikan dalam bentuk narasi.

\section{HASIL}

Distribusi tingkat kelelahan yang dialami oleh pengemudi bus malam jarak jauh PO. Restu Mulya adalah sebagai berikut.

Tabel 3. Distribusi Tingkat Kelelahan Pengemudi Bus Malam Jarak Jauh PO. Restu Mulya pada Tahun 2015

\begin{tabular}{lcc}
\hline Tingkat Kelelahan & Jumlah & Persentase \\
\hline Ringan & - & - \\
Sedang & 7 & 58,33 \\
Berat & 5 & 41,67 \\
Sangat berat & - & - \\
\hline Jumlah & 12 & 100,00 \\
\hline
\end{tabular}

Tabel 3 di atas dapat dilihat bahwa kelelahan yang dirasakan oleh pengemudi bus malam jarak jauh PO. Restu Mulya adalah kelelahan sedang dan kelelahan berat. Sebagian besar pengemudi bus malam jarak jauh PO. Restu Mulya mengalami kelelahan dengan tingkat sedang, yaitu sebanyak 7 orang dari 12 orang pengemudi $(58,33 \%)$. Sebagian pengemudi lainnya mengalami kelelahan tingkat berat yaitu sebanyak 5 orang pengemudi $(41,67 \%)$, sehingga dapat diketahui bahwa tingkat kelelahan yang dialami oleh para pengemudi bus malam jarak jauh PO. Restu Mulya adalah kelelahan tingkat sedang dan kelelahan tingkat berat.

Gejala keluhan kelelahan yang dirasakan oleh para pengemudi bus malam jarak jauh PO. Restu Mulya dapat dibedakan menjadi 3 gejala kelelahan yaitu gejala pelemahan kegiatan, gejala pelemahan motivasi, dan gejala berupa keadaan umum kelelahan fisik. Gejala kelelahan berupa pelemahan kegiatan dapat dilihat pada Tabel 4.

Tabel 4 menunjukkan bahwa gejala kelelahan berupa pelemahan kegiatan yang paling banyak dirasakan oleh pengemudi bus malam jarak jauh PO. Restu Mulya ketika bekerja adalah keluhan lelah pada seluruh badan yang sering dan/atau sangat sering dirasakan oleh 11 orang pengemudi, menguap yang sering dan/atau sangat sering dirasakan oleh sebanyak 10 orang pengemudi, menjadi mengantuk yang sering dan/atau sangat sering dirasakan oleh 10 orang pengemudi, merasakan beban pada mata yang sering dan/atau sangat sering dialami oleh 10 orang pengemudi dan keluhan perasaan berat di kepala yang sering dan/atau sangat sering dirasakan
Tabel 4. Distribusi Keluhan Kelelahan berdasarkan Gejala Pelemahan Kegiatan Pengemudi Bus Malam Jarak Jauh PO. Restu Mulya pada Tahun 2015

\begin{tabular}{lrcr}
\hline \multirow{2}{*}{ Keluhan Kelelahan } & \multicolumn{2}{c}{ Jumlah } & \\
\cline { 2 - 3 } & $\begin{array}{c}\text { Kadang- } \\
\text { kadang }\end{array}$ & $\begin{array}{c}\text { Sering/ } \\
\text { sangat } \\
\text { sering }\end{array}$ & \\
\hline Perasaan berat di kepala & 2 & 10 & 12 \\
Lelah pada seluruh badan & 1 & 11 & 12 \\
Kaki merasa berat & 3 & 9 & 12 \\
Menguap & 2 & 10 & 12 \\
Merasa pikiran kacau & 11 & 1 & 12 \\
Menjadi mengantuk & 2 & 10 & 12 \\
Terasa beban pada mata & 2 & 10 & 12 \\
Kaku dan canggung & 10 & 2 & 12 \\
Tidak seimbang saat & 9 & 3 & 12 \\
berdiri & & & \\
Ingin berbaring & 3 & 9 & 12 \\
\hline
\end{tabular}

oleh 10 orang pengemudi bus malam jarak jauh PO. Restu Mulya.

Selain itu, sebagian besar pengemudi juga mengalami perasaan ingin berbaring yang sering dan/atau sangat sering dirasakan oleh sebanyak 9 orang pengemudi, serta rasa berat pada kaki yang juga sangat sering dan/atau sering dialami oleh 9 orang pengemudi bus malam jarak jauh PO. Restu Mulya.

Gejala kelelahan yang kedua yaitu berupa gejala pelemahan motivasi dapat dilihat pada tabel 5 berikut ini.

Tabel 5. Distribusi Keluhan Kelelahan berdasarkan Gejala Pelemahan Motivasi Pengemudi Bus Malam Jarak Jauh PO. Restu Mulya pada Tahun 2015

\begin{tabular}{lccc}
\hline Keluhan Kelelahan & \multicolumn{2}{l}{ Jumlah } & \\
\cline { 2 - 3 } & $\begin{array}{c}\text { Kadang- } \\
\text { kadang }\end{array}$ & $\begin{array}{c}\text { Sering/ } \\
\text { sangat } \\
\text { sering }\end{array}$ & \\
\hline Merasa susah berfikir & 11 & 1 & 12 \\
Lelah berbicara & 10 & 2 & 12 \\
Menjadi gugup & 12 & - & 12 \\
Tidak dapat konsentrasi & 12 & - & 12 \\
Tidak perhatian & 11 & 1 & 12 \\
Cenderung untuk lupa & 9 & 3 & 12 \\
Kurang kepercayaan & 12 & - & 12 \\
Cemas terhadap sesuatu & 10 & 2 & 12 \\
Sulit mengontrol sikap & 12 & - & 12 \\
Tidak tekun dalam & 12 & - & 12 \\
bekerja & & & \\
\hline
\end{tabular}


Tabel 5 diatas menunjukkan bahwa gejala kelelahan berupa pelemahan motivasi jarang dirasakan oleh para pengemudi bus malam jarak jauh PO. Restu Mulya. Gejala pelemahan kegiatan yang paling sering dirasakan yaitu kecenderungan untuk lupa yang sering dan/atau sangat sering dirasakan oleh 3 orang pengemudi, dan perasaan cemas serta malas untuk berbicara yang sering dan/atau sangat sering dirasakan oleh 2 orang pengemudi bus malam jarak jauh PO. Restu Mulya.

Sebagian besar pengemudi bus malam jarak jauh PO. Restu Mulya hanya merasakan gejala kelelahan berupa pelemahan motivasi dengan frekuensi terkadang atau jarang.

Gejala kelelahan yang berikutnya atau gejala terakhir yaitu berupa keadan umum kelelahan fisik yang dirasakan oleh pengemudi bus malam jarak jauh PO. Restu Mulya dapat diketahui seperti yang disajikan pada tabel di bawah ini.

Tabel 6. Distribusi Keluhan Kelelahan berdasarkan Gejala Keadaan Umum Kelelahan Fisik Pengemudi Bus Malam Jarak Jauh PO. Restu Mulya pada Tahun 2015

\begin{tabular}{lrcr}
\hline \multirow{2}{*}{ Keluhan Kelelahan } & \multicolumn{2}{c}{ Jumlah } & \\
\cline { 2 - 3 } & $\begin{array}{c}\text { Kadang- } \\
\text { kadang }\end{array}$ & $\begin{array}{c}\text { Sering/ } \\
\text { sangat } \\
\text { sering }\end{array}$ & \\
\hline Sakit kepala & 3 & 9 & 12 \\
Kekauan di bahu & 2 & 10 & 12 \\
Merasa nyeri di punggung & 3 & 9 & 12 \\
Merasa pernafasan tertekan & 12 & - & 12 \\
Haus & 12 & - & 12 \\
Suara serak & 7 & 5 & 12 \\
Pening & 8 & 4 & 12 \\
Spasme di kelopak mata & 1 & 11 & 12 \\
Tremor pada anggota badan & 10 & 2 & 12 \\
Merasa kurang sehat & 8 & 4 & 12 \\
\hline
\end{tabular}

Tabel 6 menunjukkan bahwa gejala yang paling banyak menggambarkan keadaan umum pengemudi bus malam jarak jauh PO. Restu Mulya mengalami kelelahan fisik adalah berupa spasme pada kelopak mata yang sering dan/atau sangat sering dirasakan oleh 11 orang pengemudi dan rasa kaku di bahu yang sering dan/atau sangat sering dirasakan oleh 10 orang pengemudi. Sebanyak 9 orang pengemudi bus malam jarak jauh PO. Restu Mulya merasakan sering dan/atau sangat sering mengalami sakit kepala. Sebanyak 9 orang pengemudi bus malam jarak jauh PO. Restu Mulya juga mengalami rasa nyeri di bagian punggung yang dirasakan dengan sering dan/atau sangat sering.
Gejala kelelahan lainnya yang menunjukkan keadaan umum kelelahan fisik pada pengemudi bus malam jarak jauh PO. Restu Mulya adalah seperti terasa adanya tekanan pada pernafasan, perasaan haus, suara serak, terasa pening, adanya tremor atau gemetar pada anggota badan dan perasaan kurang sehat, hanya dirasakan secara terkadang atau jarang oleh sebagian besar pengemudi bus malam jarak jauh PO. Restu Mulya ketika bekerja.

Hasil penelitian menunjukkan bahwa gejala keluhan kelelahan yang paling sering dan/atau sangat sering dirasakan oleh pengemudi bus malam jarak jauh PO. Restu Mulya adalah keluhan pelemahan kegiatan dan keadaan umum kelelahan fisik.

Keluhan pelemahan kegiatan yang dirasakan oleh pengemudi bus malam jarak jauh PO. Restu Mulya antara lain adalah dengan gejala yang timbul yaitu antara lain seperti perasaan berat di kepala, lelah pada seluruh badan, menguap, mengantuk, terasa beban di mata dan perasaan ingin berbaring yang seringkali dirasakan oleh pengemudi bus malam jarak jauh PO. Restu Mulya setiap kali bekerja mengemudikan bus.

Keluhan kelelahan berupa keadaan umum dari kelelahan fisik yang banyak dirasakan oleh sebagian besar pengemudi bus malam jarak jauh PO. Restu Mulya antara lain adalah seperti sakit kepala, nyeri di punggung, rasa kaku di bagian bahu, serta spasme pada kelopak mata yang dialami dengan frekuensi sangat sering dan/atau sering setiap kali bekerja mengemudikan bus jurusan Surabaya-Denpasar.

Distribusi keluhan muskuloskeletal yang dirasakan oleh pengemudi bus malam jarak jauh PO. Restu Mulya dapat dilihat pada tabel di bawah ini.

Tabel 7. Distribusi Keluhan Muskuloskeletal Pengemudi Bus Malam Jarak Jauh PO. Restu Mulya pada Tahun 2015

\begin{tabular}{lcc}
\hline \multicolumn{1}{c}{$\begin{array}{c}\text { Keluhan } \\
\text { Muskuloskeletal }\end{array}$} & Jumlah & Persentase \\
\hline Tidak Sakit & 2 & 16,67 \\
Agak Sakit & 9 & 75,00 \\
Sakit & 1 & 8,33 \\
Sangat Sakit & - & - \\
\hline Jumlah & 12 & 100,00 \\
\hline
\end{tabular}

Tabel 7 diatas menunjukkan bahwa keluhan muskuloskeletal yang dialami oleh pengemudi bus malam jarak jauh PO. Restu Mulya memiliki tingkat antara tidak sakit hingga sakit. Sebagian besar pengemudi mengalami keluhan agak sakit yaitu sebanyak 9 orang pengemudi (75\%).Sebanyak 1 
orang pengemudi $(8,33 \%)$ mengalami keluhan sakit dan sejumlah 2 orang pengemudi lainnya $(16,67 \%)$ mengalami keluhan tidak sakit.

Hasil wawancara yang dilakukan kepada responden, diketahui bahwa keluhan muskuloskeletal yang dialami oleh para pengemudi bus malam jarak jauh PO. Restu Mulya ini timbul hanya pada saat pengemudi bekerja mengemudikan bus terutama apabila telah menempuh 5 atau 6 perjalanan Surabaya-Denpasar pergi pulang.

Selain itu keluhan muskuloskeletal yang dirasakan oleh para pengemudi bus malam jarak jauh PO. Restu Mulya ini biasanya akan hilang setelah digunakan untuk beristirahat. Sehingga keluhan tersebut hanya dirasakan saat bekerja hingga pengemudi beristirahat. Setelah beristirahat dan sebelum memulai untuk bekerja lagi pengemudi tidak merasakan adanya keluhan muskuloskeletal.

Keluhan muskuloskeletal berupa rasa sakit yang dirasakan pada beberapa bagian tubuh pengemudi bus malam jarak jauh PO. Restu Mulya dengan tingkat tidak sakit hingga sakit ini berada pada beberapa titik tertentu tubuh yang dapat diketahui melalui tabel 8 di bawah ini.

Tabel 8. Distribusi Titik Keluhan Sakit Muskuloskeletal Pengemudi Bus Malam Jarak Jauh PO. Restu Mulya pada Tahun 2015

\begin{tabular}{lcc}
\hline \multicolumn{1}{c}{ Titik Keluhan Sakit } & Jumlah & Persentase \\
\hline Leher atas & 6 & 50,00 \\
Leher bawah & 7 & 58,33 \\
Bahu kiri & 2 & 16,67 \\
Lengan atas kiri & 1 & 8,33 \\
Punggung & 4 & 33,33 \\
Lengan atas kanan & 1 & 8,33 \\
Pinggang & 9 & 75,00 \\
Bokong (buttock) & 11 & 91,67 \\
Pantat & 12 & 100,00 \\
Siku kiri & 1 & 8,33 \\
Lengan bawah kanan & 1 & 8,33 \\
Tangan kiri & 2 & 8,33 \\
Tangan kanan & 1 & 16,67 \\
Paha kiri & 1 & 8,33 \\
Paha kanan & 3 & 25,00 \\
Lutut kanan & 1 & 8,33 \\
Betis kiri & 5 & 41,67 \\
Betis kanan & 7 & 58,33 \\
Pergelangan kaki kiri & 1 & 8,33 \\
Pergelangan kaki kanan & 3 & 25,00 \\
Kaki kiri & 1 & 8,33 \\
Kaki kanan & 2 & 16,67 \\
\hline
\end{tabular}

Tabel diatas menunjukkan bahwa terdapat beberapa titik sakit yang paling banyak atau paling sering dikeluhkan oleh para pengemudi bus malam jarak jauh PO. Restu Mulya. Terdapat satu titik keluhan yang dirasakan sakit oleh seluruh pengemudi bus malam jarak jauh PO. Restu Mulya ketika bekerja yaitu keluhan pada pantat yang dialami oleh 12 orang pengemudi (100\%). Sebagian besar pengemudi bus malam jarak jauh PO. Restu Mulya juga merasakan keluhan sakit pada bokong (buttock) yang dialami oleh 11 orang pengemudi (91,67\%), dan keluhan sakit pada pinggang yang dialami oleh 9 orang pengemudi (75\%) setiap kali bekerja mengemudikan bus.

Keluhan lain yang juga dirasakan oleh sebagian besar pengemudi adalah keluhan sakit pada betis kaki yaitu pada betis sebelah kanan yang dialami oleh 7 orang pengemudi $(58,33 \%)$ dan betis sebelah kiri yang dialami oleh 5 orang pengemudi $(41,67 \%)$. Keluhan sakit juga dirasakan pada leher yaitu leher bagian atas yang dialami oleh 6 orang pengemudi (50\%) dan leher bagian bawah yang dikeluhkan oleh $58,33 \%$ pengemudi atau sebanyak 7 orang pengemudi.

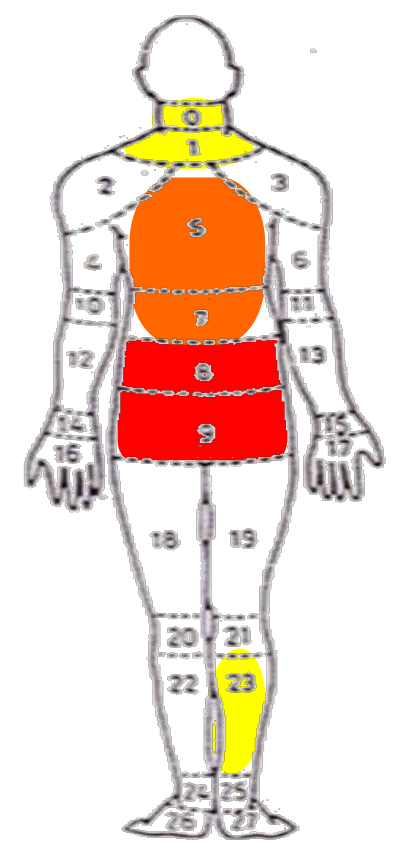

Gambar 1. Pemetaan/Mapping Titik Keluhan Muskuloskeletal pada Pengemudi Bus Malam Jarak Jauh PO. Restu Mulya

\footnotetext{
Keterangan:

$=$ sangat sakit
$=$ sakit

= agak sakit
} 
Hasil penelitian yang telah didapatkan menunjukkan bahwa titik keluhan sakit yang dialami oleh pengemudi bus malam jarak jauh PO. Restu Mulya tersebut dapat digambarkan pada bagan NBM (Nordic Body Map) pada gambar 1, untuk mendapatkan gambaran pemetaan atau mapping dari keluhan muskuloskeletal yang dialami oleh para pengemudi bus malam jarak jauh PO. Restu Mulya.

Gambar 1 menunjukkan bahwa pada pekerjaan mengemudikan bus oleh pengemudi bus malam jarak jauh PO. Restu Mulya memiliki titik yang sangat berisiko terhadap keluhan sangat sakit yaitu pada titik tubuh nomor 8 dan titik tubuh nomor 9 atau terdapat pada bagian bokong (buttock) dan pantat. Sedangkan titik yang sangat berisiko terhadap keluhan sakit adalah titik tubuh nomor 5 dan titik tubuh nomor 7 , yaitu pada bagian punggung dan pinggang.

Titik tubuh lainnya yang juga berisiko mengalami keluhan muskuloskeletal adalah pada titik tubuh nomor 0 dan titik tubuh nomor 1 , yaitu pada leher bagian atas dan pada leher bagian bawah, serta pada titik tubuh nomor 23 yaitu pada bagian betis sebelah kanan.

\section{PEMBAHASAN}

Tingkat kelelahan yang dialami oleh pengemudi bus malam jarak jauh PO. Restu Mulya merupakan kelelahan tingkat sedang dan kelelahan tingkat berat. Kelelahan pada pengemudi bus malam jarak jauh PO. Restu Mulya ini memiliki tingkat yang lebih tinggi apabila dibandingkan dengan hasil penelitian oleh Umyati dkk (2015), tentang kelelahan pada pengemudi bus jarak dekat yaitu dengan trayek jurusan Kalideres-Merak yang mendapatkan hasil bahwa $100 \%$ pengemudi bus jarak dekat hanya mengalami kelelahan dengan tingkat ringan.

Penelitian oleh Hakim (2011), pada petugas ATC (Air Traffic Controller) Bandara Juanda Surabaya juga menunjukkan hasil yang lebih rendah yaitu hanya terdapat $6,3 \%$ petugas dengan tingkat kelelahan berat, $81,3 \%$ petugas dengan tingkat kelelahan sedang serta $12,5 \%$ petugas dengan tingkat kelelahan ringan.

Hasil penelitian menunjukkan bahwa kelompok pekerja pengemudi bus malam dengan jarak jauh seperti pada jurusan Surabaya-Denpasar memiliki risiko kelelahan yang lebih tinggi dibandingkan dengan pekerjaan sejenis yang memiliki beban kerja lebih ringan atau pada pekerjaan jenis lainnya.
Jenis kelelahan yang dialami oleh pengemudi bus malam jarak jauh PO. Restu Mulya adalah kelelahan umum dengan keluhan kelelahan yang paling banyak dirasakan berupa pelemahan kegiatan dan kelelahan fisik. Kelelahan umum ini ditandai dengan menurunnya kemauan untuk bekerja melalui beberapa gejala yang dirasakan seperti perasaan berat di kepala, lelah pada seluruh badan, menguap, perasaan mengantuk, terasa beban di mata, perasaan ingin berbaring, sakit kepala, nyeri di bagian punggung, terasa kaku di bagian bahu, serta spasme pada kelopak mata (Suma'mur, 2009).

Kelelahan pada pengemudi bus malam jarak jauh PO. Restu Mulya ini dimungkinkan karena intensitas kerja mental dan fisik yang tinggi, serta dalam waktu yang lama. Intensitas kerja fisik dan mental yang tinggi ini merupakan beban kerja fisik dan beban kerja psikologis yang diterima oleh pengemudi bus malam jarak jauh PO. Restu Mulya pada setiap kali bekerja.

Dalam setiap perjalanan, pengemudi akan mengemudi selama 10-12 jam pada malam hari dengan waktu istirahat saat kerja yang sangat singkat yaitu antara 1-1,5 jam. Lamanya waktu kerja dan waktu istirahat yang cukup akan sangat menentukan efektivitas dan produktivitas kerja. Pada umumnya manusia akan optimal bila bekerja dengan batas waktu maksimal 8 jam dalam satu hari, pekerja yang bekerja dengan lama waktu kerja yang melebihi 8 jam dalam satu hari akan menurunkan produktivitas dan efektivitas karena meningkatkan risiko kelelahan bagi pekerja (Wignjosoebroto, 2008).

Pengemudi bus malam yang bekerja pada malam hari akan lebih meningkatkan risiko kelelahan, membutuhkan waktu istirahat yang lebih lama serta asupan kalori yang lebih tinggi. Waktu istirahat yang didapatkan pada saat bekerja yang kurang dari cukup yaitu minimal $20-30 \%$ dari total waktu bekerja juga akan berpengaruh pada pemulihan tenaga dan stamina yang terpakai pada saat kerja sehingga dapat meningkatkan risiko kelelahan (Suma'mur, 2009).

Selama perjalanan pengemudi juga melakukan sikap kerja yang monoton yaitu hanya dengan duduk tanpa ada perubahan sikap kerja lainnya sehingga akan menyebabkan timbulnya perasaan jemu, kejenuhan dan kebosanan yang juga berpengaruh terhadap timbulnya perasaan lelah (Setyawati, 2010). Selain itu, selama bekerja pengemudi bus malam jarak jauh dituntut untuk terus berkonsentrasi tinggi ketika mengemudi untuk kesiapsiagaan dan kewaspadaan penuh agar terhindar dari kejadian yang tidak diinginkan. Bekerja dengan konsentrasi 
dan ketelitian tinggi akan membutuhkan kinerja otak yang berat sehingga meningkatkan risiko kelelahan (Suma'mur, 2009).

Kelelahan yang terjadi pada pengemudi bus malam jarak jauh bukan hanya diakibatkan oleh kondisi ketika bekerja namun dapat pula karena kondisi sebelum dan setelah bekerja. Setelah bekerja, pengemudi bus tidak lantas dapat langsung beristirahat karena perlu untuk membersihkan kendaraannya, melakukan pengecekan, dan halhal lainnya yang dilakukan setelah perjalanan. Sedangkan sebelum bekerja, pengemudi bus malam jarak jauh juga perlu untuk menunggu penumpang, menaikkan barang bawaan penumpang, dan akumulasi kelelahan sebelumnya serta berbagai permasalahan psikologis yang mungkin saja dimiliki oleh pengemudi sehingga dapat menjadi penyebab kelelahan di luar kondisi bekerja pengemudi bus malam jarak jauh.

Tingkat kelelahan sedang dan kelelahan tingkat berat yang dialami oleh pengemudi bus malam jarak jauh PO. Restu Mulya ini memerlukan asupan kalori kerja yang sesuai dan waktu istirahat yang cukup ketika kerja untuk menekan timbulnya perasaan lelah. Waktu istirahat setelah kerja yang cukup lama juga diperlukan untuk mengembalikan kebugaran dan stamina tubuh pengemudi sebelum kembali bekerja lagi (Wignjosoebroto, 2008).

Hal lain terkait kelelahan yang perlu dan sangat penting untuk diperhatikan adalah status kesehatan pengemudi. Pengemudi yang bekerja dengan kondisi kesehatan yang kurang baik atau pernah memiliki suatu riwayat penyakit tertentu akan sangat berpengaruh terhadap imunitas tubuhnya sehingga berisiko besar mengalami kelelahan pada waktu bekerja. Waktu istirahat dan asupan kalori kerja yang diterima oleh pengemudi bus malam jarak jauh PO. Restu Mulya menjadi salah satu faktor penting dalam menentukan status kesehatan pengemudi karena waktu istirahat yang cukup dapat mencegah tubuh dari kerusakan, serta asupan kalori kerja secara jangka panjang juga menentukan status kesehatan pekerja (Tarwaka dkk, 2004).

Pengkondisian lingkungan kerja secara optimum juga diperlukan agar pengemudi tetap nyaman selama bekerja dan menekan timbulnya perasaan kelelahan. Adapun pengkondisian lingkungan tersebut dapat dilakukan dengan mengatur suhu ruangan di dalam kabin bus, serta perawatan yang dilakukan oleh pihak perusahaan dan pemantauan dari pihak terkait agar bus yang dikemudikan oleh pengemudi bus malam jarak jauh tetap aman dan nyaman untuk bekerja. Perawatan tersebut berguna untuk memastikan pengatur suhu ruangan di dalam kabin bus bekerja dengan baik, kondisi mesin, karet mesin, peredam mesin, dan kondisi suspensi serta berbagai komponen dan piranti peralatan penunjang lainnya pada bus tidak menimbulkan gangguan baik secara langsung maupun tidak langsung bagi pengemudi seperti kebisingan dan getaran selama dalam perjalanan (Wignjosoebroto, 2008).

Hasil penelitian menunjukkan bahwa sebagian besar pengemudi bus malam jarak jauh PO. Restu Mulya mengalami keluhan muskuloskeletal tingkat ringan. Hasil penelitian Aditya (2010), juga menyebutkan bahwa 100\% pengemudi bus jarak jauh hanya mengalami keluhan muskuloskeletal tingkat ringan. Hal ini dapat dikarenakan oleh desain stasiun kerja di dalam kabin atau ruangan bus telah ergonomis yaitu telah terdapat kesesuaian antara ukuran stasiun kerja dengan ukuran tubuh para pekerja selama pengemudi bekerja mengemudikan bus malam jarak jauh (Tarwaka dkk, 2004).

Stasiun kerja pengemudi bus yaitu kursi pengemudi yang terletak di dalam kabin bus telah dilengkapi dengan berbagai tuas pengatur (setting lever) seperti tuas pengatur ketinggian kursi pengemudi, tuas pengatur jarak kursi pengemudi dengan setir, tuas pengatur sudut sandaran kursi pengemudi, serta tuas pengatur ketinggian setir kemudi seperti pada gambar di bawah ini yang dapat diatur agar lebih sesuai dan nyaman dengan ukuran tubuh pengemudi sehingga menciptakan stasiun kerja yang ergonomis dan sikap kerja yang alamiah (Tarwaka dkk, 2004).

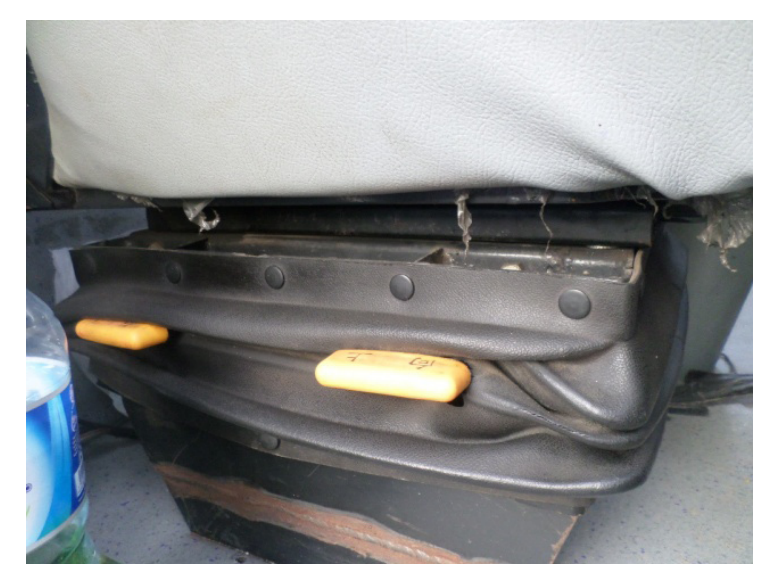

Gambar 2. Salah Satu Tuas Pengatur (setting lever) yang Ada pada Kursi Pengemudi

Apabila dilihat dari jenis keluhan yang timbul pada pekerja, maka keluhan tingkat ringan yang 
dirasakan oleh pengemudi bus malam jarak jauh PO. Restu Mulya memiliki jenis keluhan sementara (reversible) yaitu keluhan muskuloskeletal hanya muncul pada saat bekerja dan akan hilang dengan sendirinya ketika selesai bekerja serta digunakan untuk beristirahat. Jenis keluhan sementara (reversible) dan tingkat keluhan yang ringan bagi pengemudi bus malam jarak jauh ini belum dan/ atau tidak memerlukan suatu terapi atau pengobatan khusus.

Hal ini dikarenakan keluhan tingkat ringan dapat dikatakan bukan sebagai suatu permasalahan, dan jenis keluhan sementara (reversible) hanya muncul ketika bekerja yaitu terjadi pembebanan pada bagian otot secara berlebihan namun akan hilang dengan sendirinya setelah selesai bekerja atau beristirahat karena bagian otot yang digunakan untuk bekerja telah tidak diberikan pembebanan. Sehingga keluhan muskuloskeletal ini belum diperlukan suatu tindakan serius untuk terapi ataupun pengobatannya (Tarwaka dkk, 2004).

Hal yang perlu diperhatikan adalah kursi pengemudi di dalam kabin bus dan jarak peralatan maupun piranti lainnya pada panel kemudi (dashboard) yang perlu dijangkau oleh pengemudi ketika bekerja agar diatur sedemikian rupa sehingga menciptakan stasiun kerja yang nyaman dan ergonomis. Dengan stasiun kerja yang nyaman serta ergonomis dan sesuai dengan ukuran antropometri pekerja maka hal ini bertujuan agar pengemudi terhindar dari sikap paksa selama bekerja mengemudikan bus malam jarak jauh sehingga dapat menekan timbulnya gangguan kesehatan seperti keluhan muskuloskeletal. Penambahan busa dan bantal pada kursi pengemudi juga dapat menjadikan salah satu alternatif untuk menciptakan ergonomi pada stasiun kerja dan juga dapat lebih memberikan perasaan nyaman bagi pengemudi.

Jarak jangkauan maksimum dan jangkauan normal pada stasiun kerja pengemudi bus malam jarak jauh juga sesuai dengan standar area kerja sehingga pengemudi tidak memerlukan perubahan posisi tubuh ketika menjangkau peralatan maupun piranti lainnya pada panel kemudi (dashboard). Hal ini sangatlah penting untuk memudahkan pekerja dalam bekerja (Wignjosoebroto, 2008).

Keluhan muskuloskeletal yang dirasakan oleh pengemudi bus malam jarak jauh PO. Restu Mulya walaupun hanya bersifat ringan dan sementara, namun terdapat beberapa titik otot yang sangat sering atau bahkan hampir selalu dikeluhkan oleh para pengemudi mengalami keluhan sakit. Beberapa

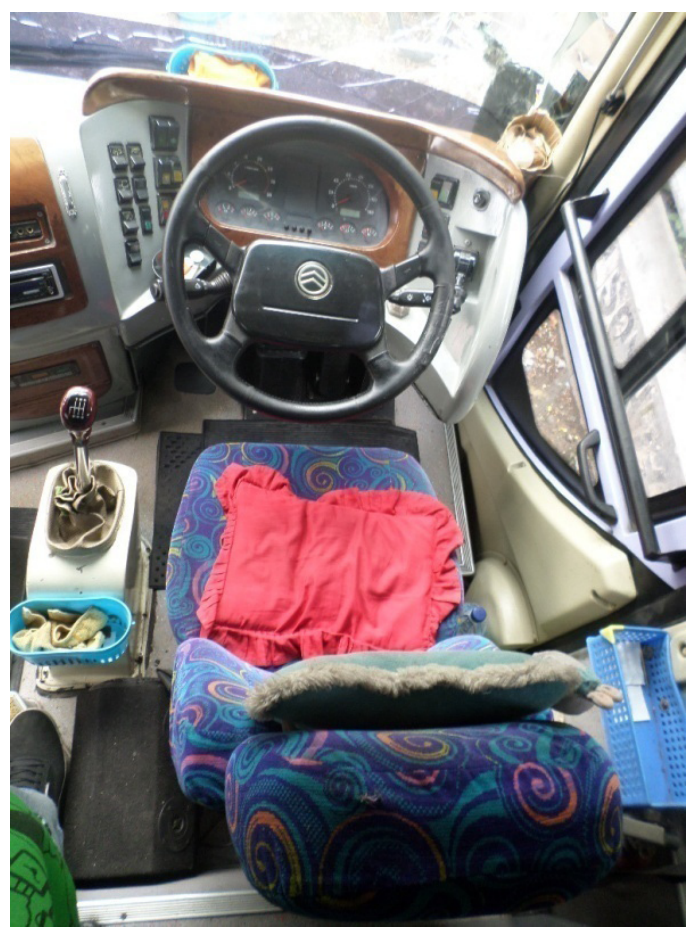

Gambar 3. Jangkauan Kerja pada Stasiun Kerja Pengemudi Bus Malam Jarak Jauh dan Penambahan Bantal pada Kursi Pengemudi

titik keluhan sakit tersebut antara lain adalah pantat, bokong, pinggang, betis kanan dan leher. Hal ini sesuai dengan teori dari Tarwaka dkk (2004), yang menyebutkan bahwa beberapa bagian otot ini yaitu seperti leher punggung, pinggang, dan otot bagian bawah merupakan bagian yang paling sering dikeluhkan oleh pekerja yang melakukan sikap kerja duduk.

Sikap kerja duduk memiliki beberapa keuntungan antara lain yaitu pengurangan terhadap pembebanan pusat berat tubuh terhadap kaki dan pengurangan pemakaian energi. Sikap kerja duduk juga sesuai untuk pekerjaan yang membutuhkan konsentrasi tinggi, pekerjaan yang membutuhkan ketelitian dan kontrol pada kaki, serta pekerjaan yang dilakukan dalam waktu yang lama (Tarwaka dkk, 2004).

Beberapa titik otot yang sangat sering atau hampir selalu dikeluhkan oleh para pengemudi bus malam jarak jauh PO. Restu Mulya yang mengalami keluhan sakit antara lain adalah pantat, bokong, pinggang, betis kanan dan leher. Hasil penelitian ini sesuai dengan penelitian lainnya yaitu penelitian oleh Aditya (2010), yang mendapatkan hasil sebesar $72,9 \%$ pengemudi bus jarak jauh mengalami gangguan pinggang. 
Hal ini dapat disebabkan oleh karena kondisi duduk dalam waktu yang sangat lama atau melebihi batas waktu kerja optimum dari seorang pekerja yaitu antara 10-12 jam pada setiap perjalanan merupakan suatu keadaan monoton yang menyebabkan pembebanan statis bagi otot pinggang, pantat, dan bokong. Mengemudi dalam waktu yang sangat lama juga akan meningkatkan risiko timbulnya nyeri pada otot pantat dan bokong sebesar 3 kali lipat sehingga titik tersebut akan sangat sering mengalami gangguan berupa keluhan muskuloskeletal (Nurmianto, 2004).

Berbeda dengan sikap kerja berdiri yang memiliki titik pembebanan berat tubuh pada kaki, sikap kerja duduk memiliki titik pembebanan berat tubuh yang terletak pada bagian pantat dan bokong karena menopang ruas tulang belakang sehingga bagian bokong dan pantat akan lebih berisiko mengalami gangguan kesehatan (Tarwaka dkk, 2004). Sikap kerja duduk juga dapat menyebabkan melembeknya otot perut dan melengkungnya tulang belakang sehingga tubuh pekerja dengan sikap kerja duduk akan cenderung membungkuk dan berpengaruh terhadap kesehatan pinggang dan punggung.

Posisi sandaran duduk dari pengemudi bus malam jarak jauh selama bekerja mengemudikan bus juga berpengaruh terhadap timbulnya keluhan muskuloskeletal pada pinggang, pantat, dan bokong. Dengan posisi sandaran yang membentuk sudut $>90^{\circ}$ akan mengurangi pembebanan berat tubuh pada pantat, pinggan dan bokong sebesar $10-20 \%$. Posisi sandaran duduk yang semakin tegak $\left(\leq 90^{\circ}\right)$ akan meningkatkan risiko keluhan muskuloskeletal pada pinggang, pantat dan bokong karena pembebanan tubuh akan meningkat hinggal $40 \%$ (Siswanto, 2006).

Selama mengemudi, pandangan pengemudi akan terfokus ke depan dengan konsentrasi, ketelitian, dan kewaspadaan tinggi sehingga hal ini berpengaruh terhadap ketegangan otot bagian leher sehingga berisiko mengalami keluhan muskuloskeletal. Bagian otot lainnya yang berisiko mengalami keluhan sakit adalah pada betis kanan.

Hal ini dikarenakan pekerjaan mengemudi adalah pekerjaan yang mengkoordinasikan kemampuan otak, mata, tangan, dan kaki, serta membutuhkan ketelitian dan konsentrasi tinggi pada kaki. Terlebih lagi adalah pada kaki kanan pengemudi bus malam jarak jauh, pada pekerjaan mengemudi kaki kanan memainkan peranan untuk laju kendaraan dengan digunakan untuk menginjak pedal gas dan pedal rem. Sehingga beban kerja kaki kanan lebih tinggi daripada beban kerja kaki kiri dan kaki kanan akan lebih berpotensi mengalami keluhan muskuloskeletal.

\section{SIMPULAN}

Kelelahan yang dialami oleh pengemudi bus malam jarak jauh PO. Restu Mulya merupakan kelelahan tingkat sedang dan berat dengan keluhan berupa pelemahan kegiatan dan kelelahan fisik. Gejala kelelahan yang dirasakan antara lain adalah perasaan berat dan sakit di kepala, lelah pada seluruh badan, menguap, perasaan mengantuk, spasme dan terasa beban di mata, perasaan ingin berbaring, nyeri dan terasa kaku di bagian punggung dan bagian bahu. Penyebab kelelahan pada pengemudi bus malam jarak jauh PO. Restu Mulya antara lain adalah tingginya beban kerja mental dan fisik seperti pekerjaan yang dilakukan pada malam hari dan besarnya tanggung jawab pengemudi terhadap kenyamanan dan keselamatan penumpang.

Pengemudi bus malam jarak jauh PO. Restu Mulya merasakan keluhan muskuloskeletal agak sakit dengan titik keluhan yang paling banyak muncul yaitu pada bokong (buttock), pantat, pinggang, punggung, leher, dan betis kanan. Penyebab dari keluhan muskuloskeletal ini antara lain adalah monotoni sikap kerja duduk secara statis dalam waktu yang sangat lama.

\section{DAFTAR PUSTAKA}

Aditya, Reza. 2010. Beberapa Faktor yang Berhubungan dengan Gangguan Nyeri Punggung Bawah pada Pengemudi Bus (Studi kasus pengemudi bus di Perum DAMRI Ponorogo). Skripsi. Surabaya: Universitas Airlangga.

Fahmi, Rahmadi. 2015. Faktor yang Berhubungan dengan Kelelahan dan Keluhan Muskuloskeletal pada Pengemudi Bus Malam PO. Restu Mulya Jurusan Surabaya-Denpasar. Skripsi. Surabaya: Universitas Airlangga.

Hakim, Fahmi. 2011. Gambaran Tingkat Kelelahan pada Petugas Tower Control ATC di Bandara Internasional Juanda Surabaya. Skripsi. Surabaya: Universitas Airlangga.

Namira, Sangadji W., Nurhayati. 2014. Hipertensi pada Pramudi Bus Transjakarta di PT. Bianglala

Metropolitan Tahun 2013. Indonesian Public Health Student Journal Volume 2 No. 2/Januari-Juni 2014. Hal. 1-10. 
Nurmianto, Eko. 2004. Ergonomi, Konsep Dasar dan Aplikasinya. Jakarta: Guna Widya.

Setyawati, L. 2010. Selintas tentang Kelelahan Kerja. Yogyakarta: Amara Books.

Siswanto, A. 2006. Low Back Pain. Buku Ajar. Surabaya: Universitas Airlangga.

Suma'mur. 2009. Higiene Perusahaan dan Kesehatan Kerja. Jakarta: CV Sagung Seto.

Tarwaka., Solikhul HA., Bakri, Sudiajeng L. 2004. Ergonomi Untuk Kesehatan, Keselamatan Kerja, dan Produktivitas. Surakarta: Uniba Press.

Tarwaka. 2010. Dasar-Dasar Pengetahuan Ergonomi dan Aplikasi di Tempat Kerja. Solo: Harapan Press Solo.
Umyati, Ani., Yayan Harry Yadi., Eka Setia Norma Sandi. 2015. Pengukuran Kelelahan Kerja Pengemudi Bis dengan Aspek Fisiologis Kerja dan Metode Industrial Fatique Research Committee (IFRC). Seminar Nasional IENACO - 2015 ISSN 2337-4349. Hal. 163-171. Banten: Universitas Sultan Ageng Tirtayasa.

Wignjosoebroto, S. 2008. Ergonomi, Studi Gerak dan Waktu. Jakarta: PT. Guna Widya.

Yogisutanti, Gurdani., Kusnanto, Hari., Setyawati, Lientje., Otsuka, Yasumasa.2013. Kebiasaan Makan Pagi, Lama Tidur dan Kelelahan Kerja (Fatigue) Pada Dosen. Jurnal Kesehatan Masyarakat. KEMAS 9 (1) (2013) 53-57. Semarang: Universitas Negeri Semarang. 